\title{
Synthesis, properties, and electrogenerated chemiluminescence (ECL) of a novel carbazole-based chromophore
}

\author{
Ken-Tsung Wong, ${ }^{*}$ Tsung-Hsi Hung, Teng-Chih Chao and Tong-Ing Ho* \\ Department of Chemistry, National Taiwan University, Taipei 106, Taiwan
}

Received 3 August 2004; revised 22 November 2004; accepted 25 November 2004

Available online 18 December 2004

\begin{abstract}
A novel molecule containing electron-rich carbazole and electron-deficient pyrimidine moieties exhibits useful and intriguing physical properties, including promising reversible redox behavior that gives rise to electrogenerated chemiluminescence (ECL).

(C) 2004 Elsevier Ltd. All rights reserved.
\end{abstract}

Electrogenerated chemiluminescence (ECL) has widely been applied as a sensitive and selective detecting technique for many analytical applications; ${ }^{1}$ it is also an excellent model for investigating the mechanism of electron transfer. ${ }^{2}$ ECL is a process that involves photon generation by homogeneous electron transfer (ET) between electrochemically generated radical cations and radical anions that form in close proximity to the electrode surface in an ECL cell. ${ }^{3}$ Upon sweeping sequentially between negative and positive potentials over a short-time interval, the excited states of the electroactive species can be made to populate emitting states that subsequently relax to ground states with the emission of light of appropriate wavelengths. Both singlet and triplet states of the electroactive species can be formed depending on the annihilation enthalpy change $\left(\Delta H_{\mathrm{ann}}\right)$ of the electron transfer reaction. The ion annihilation process can generate a singlet state (S-route) ${ }^{4}$ if the magnitude of $\Delta H_{\text {ann }}$ is larger than the energy needed to reach the excited singlet state $\left(E_{\mathrm{s}}\right)$. On the other hand, if the value of $\Delta H_{\mathrm{ann}}$ is lower than that of $E_{\mathrm{s}}$, but it is sufficient to generate the triplet state, then the electron transfer reaction will lead to the formation of that triplet state. It is still possible, however, to form a singlet state by triplet-triplet annihilation, which is a process known as the T-route. As a consequence, fluorescence is the normal emission from the electrochemically generated excited state of an electroactive species. For practical

\footnotetext{
Keywords: Electrogenerated chemiluminescence (ECL); Carbazole; Pyrimidine.

* Corresponding authors. Tel.: +88622363 0231; fax: +88622363 6359 (K-T.W.); e-mail: kenwong@ntu.edu.tw
}

purposes, molecular systems that give rise to significant ECL are single molecules that contain one or more chromophores that exhibit reversible redox behavior. If only one of the oxidation or reduction processes is reversible, ECL has to be generated by a co-reactant process. ${ }^{5}$ In this regard, organic molecules having structural character capable of generating ECL have been explored relatively infrequently when compared to inorganic $\mathrm{Ru}(\mathrm{bpy})_{3}^{2+}$ and related complexes. ${ }^{6}$

Molecules incorporating carbazole moieties have been investigated extensively as light-emitting materials and as the hole-transporting materials in organic light-emitting devices (OLED) because of their high reversibility upon electrochemical oxidation. ${ }^{7}$ Previously, we established a feasible synthesis, using Suzuki coupling reaction, of molecules containing pyrimidine moieties. ${ }^{8}$ These pyrimidine-containing materials undergo reversible reduction processes, which suggests that they hold promise for use in light-emitting and electron transport materials. We anticipated that the preparation of a molecule that combines the individual characteristics of carbazole (i.e., electron richness) and pyrimidine (i.e., high electronegativity) moieties would afford a new kind of material. In this letter we report the synthesis and properties, including ECL behavior, of such a novel molecule.

Scheme 1 depicts the synthetic pathways we took toward the target molecule 4 . The 5,8-dibromo-1-phenylcarbazole was converted to diboronic ester 2 in an isolated yield of $72 \%$ by treating it with $n$-BuLi at $-78^{\circ} \mathrm{C}$ and then quenching the dilithiated intermediate with 2-isopropoxy-4,4,5,5-tetramethyl-[1,3,2]-dioxaborolane. 


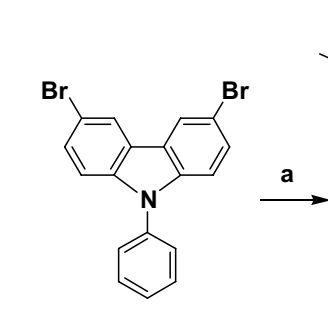

1

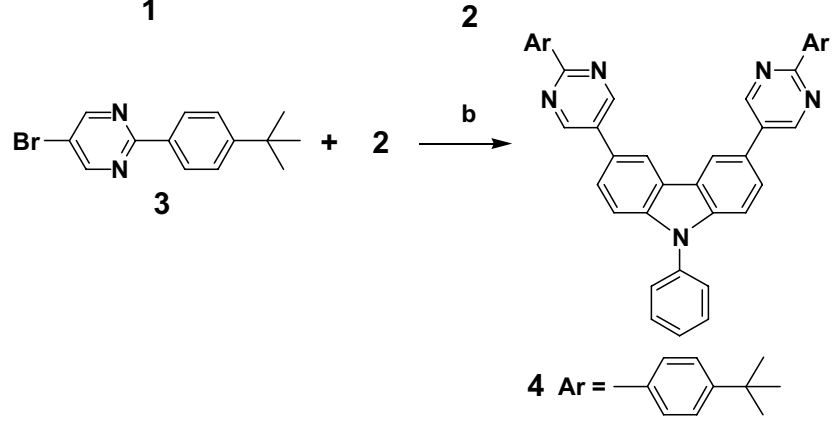

Scheme 1. Reagents and conditions: a, (i), $n$-BuLi, $-78^{\circ} \mathrm{C}$, THF; (ii), 2-isopropoxy-4,4,5,5-tetramethyl-[1,3,2]-dioxaborolane, $-78^{\circ} \mathrm{C}$ to $\mathrm{rt}$; b, $\mathrm{Pd}\left(\mathrm{PPh}_{3}\right)_{4}, \mathrm{P}^{t} \mathrm{Bu}_{3}, \mathrm{Na}_{2} \mathrm{CO}_{3}, \mathrm{PhCH}_{3}$, reflux.

The 2-(4-tert-butylphenyl)-5-bromopyrimidine 3 was synthesized according to our Suzuki coupling approach. ${ }^{8}$ The reaction of diboronic ester 2 and bromo compound $\mathbf{3}$ in the presence of a catalytic amount of $\operatorname{Pd}\left(\mathrm{PPh}_{3}\right)_{4}$ furnished the desired compound 4 in $67 \%$ yield. ${ }^{9}$

The new compound $\mathbf{4}$ exhibits high morphological stability and good resistance to thermal decomposition. During DSC analysis, molecule 4 displays a distinct glass transition $\left(T_{\mathrm{g}}\right)$ at $164{ }^{\circ} \mathrm{C}$ that is followed by crystallization $\left(T_{\mathrm{c}}\right)$ at $218^{\circ} \mathrm{C}$ and melting $\left(T_{\mathrm{m}}\right)$ at $337^{\circ} \mathrm{C}$. We attribute the crystallinity of $\mathbf{4}$ to the rigidity of its peripheral aryl substituents, even though we purposely introduced the sterically bulky, terminal tert-butyl groups to preclude significant intermolecular interactions. The rigidity of the peripheral aryl groups is also beneficial for this molecule's high thermal stability during TGA analysis: the $10 \%$-weight-loss temperature of $\mathbf{4}$, while heating $\left(20^{\circ} \mathrm{C} / \mathrm{min}\right)$ under nitrogen, is $429^{\circ} \mathrm{C}$.

We studied the electronic absorption and photoluminescence of compound 4 in different solvents $\left(\mathrm{CHCl}_{3}, \mathrm{THF}\right.$, and $\mathrm{CH}_{3} \mathrm{CN}$ ) to verify the polarized character of the chromophore. The absorption spectrum of 4 in $\mathrm{CHCl}_{3}$ is similar to that obtained in $\mathrm{CH}_{3} \mathrm{CN}$ : an absorption maximum centered at $308 \mathrm{~nm}$ and a shoulder at $343 \mathrm{~nm}$. The absorption of 4 in THF exhibits a similar shoulder, but is associated with a slightly blue-shifted absorption maximum $(299 \mathrm{~nm})$. In contrast to the electronic absorption, the emission maxima of $\mathbf{4}$ are more sensitive to the polarities of the solvents. In $\mathrm{CH}_{3} \mathrm{CN}$, a significant red shift $(22 \mathrm{~nm})$ is observed relative to the emission maxima of $\mathbf{4}$ in $\mathrm{CHCl}_{3}$ and THF (Fig. 1). We ascribe the bathochromic shift of the emission maximum in $\mathrm{CH}_{3} \mathrm{CN}$ to the polar character of $\mathbf{4}$ in this solvent that arises as a result of intramolecular charge transfer occurring in its excited state. Additionally, compound 4 is highly emissive in the solid state - it has an emission

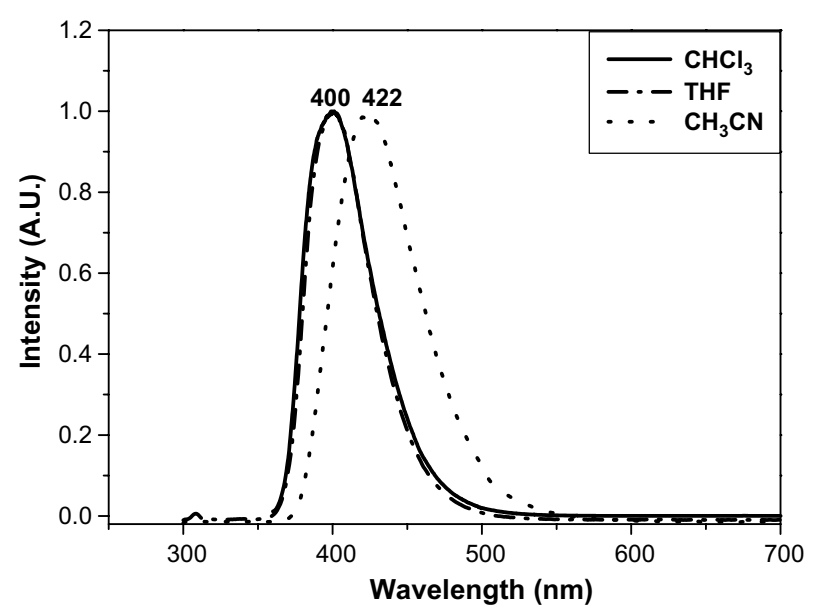

Figure 1. The photoluminescence spectra of $\mathbf{4}$ in different solvents.

maximum centered at $417 \mathrm{~nm}$ - and the quantum yield of its vacuum-deposited thin film, studied by the calibrated integrating sphere system, was determined to be 0.51 .

Next, we conducted cyclic voltammetry (CV) experiments on compound $\mathbf{4}$ at room temperature to probe its electrochemical properties. CV traces of 4 (Fig. 2) were recorded in both THF, using $0.1 \mathrm{M} n \mathrm{Bu}_{4} \mathrm{NClO}_{4}$ as the supporting electrolyte and a glassy carbon electrode as the working electrode, and $\mathrm{CH}_{2} \mathrm{Cl}_{2}$, using $0.1 \mathrm{M} n \mathrm{Bu}_{4} \mathrm{NPF}_{6}$. It appears that the structural character of $\mathbf{4}$ has a beneficial effect on the reversibility of the electrochemical processes. In THF, a quasi-reversible reduction potential is evident at a value of $E_{p, c}$ of $-2.29 \mathrm{~V}$ ( $\mathrm{vs} \mathrm{Ag} / \mathrm{AgCl}$ ). It is reasonable to attribute this reduction to the injection of electrons from the electrode to the pyrimidine moieties of $\mathbf{4}$. The anodic oxidation of 4 in THF displays less-reversible electrochemical behavior with a value of $E_{p, a}$ of $1.60 \mathrm{~V}$ ( $\left.\mathrm{vs} \mathrm{Ag} / \mathrm{AgCl}\right)$. This result indicates possibly that the radical cation of $\mathbf{4}$ has relatively low stability in THF. To support this hypothesis, we conducted the oxidation $\mathrm{CV}$ experiment of $\mathbf{4}$ in $\mathrm{CH}_{2} \mathrm{Cl}_{2}$ using $0.1 \mathrm{M} n \mathrm{Bu}_{4} \mathrm{NPF}_{6}$ as the supporting

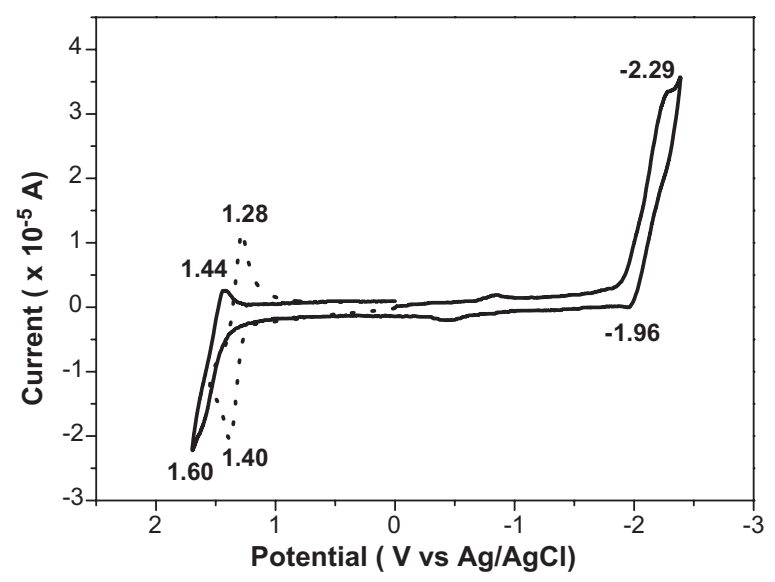

Figure 2. Cyclic voltammograms of 4 recorded in THF (solid line),

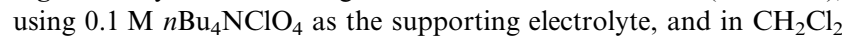
(dot line), using $0.1 \mathrm{M} n \mathrm{Bu}_{4} \mathrm{NPF}_{6}$. 


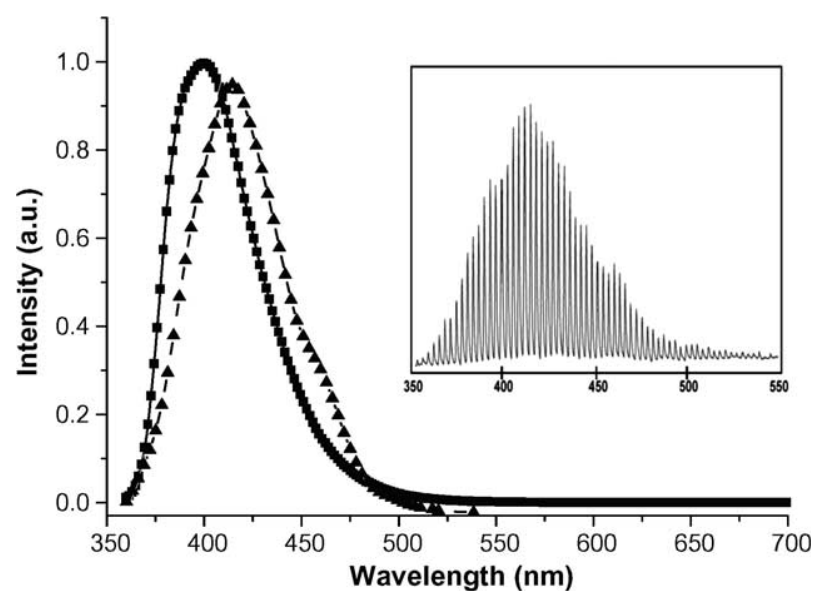

Figure 3. Photoluminescence ( $\square$ ) and 10-point-smoothed ( $\boldsymbol{\Delta}$ ) electrogenerated chemiluminescence (ECL) spectra. The inset presents the original ECL spectrum.

electrolyte. In this case, we detected a reversible oxidation process $\left[E_{1 / 2}=1.34 \mathrm{~V}\right.$ ( $\left.\left.\mathrm{vs} \mathrm{Ag} / \mathrm{AgCl}\right)\right]$. We believe that the reversible oxidation originates from the hole injection at the central carbazole unit. The electrochemical data reveal that the electrogenerated radical ions are stable and that efficient ECL can occur as a result of ion annihilation.

The ECL of $\mathbf{4}$ in THF was measured according to our previously published method. ${ }^{10}$ Figure 3 presents the ECL spectrum of 4 recorded between $-2.0 \mathrm{~V}(0.5 \mathrm{~s})$ and $+0.8 \mathrm{~V}(0.5 \mathrm{~s})$ at $2 \mathrm{~s}$ intervals.

The photoluminescence spectrum of $\mathbf{4}$ in THF closely resembles its ECL spectrum, but the maximum intensity in the ECL spectrum is slightly red-shifted (ca. $14 \mathrm{~nm}$ ) relative to the fluorescence maximum. We believe that this shift arises because of the higher polarity of the THF solution containing the $n \mathrm{Bu}_{4} \mathrm{NClO}_{4}$ electrolyte. The absence of a long-wavelength emission in the ECL spectrum excludes the formation of an excimer (E-route) during the ion annihilation process. The energy available for this ion annihilation reaction is given by the following equation: ${ }^{11}$

$$
\left|\Delta H_{\mathrm{ann}}\right|=E_{\mathrm{p}}\left(\mathbf{4} / \mathbf{4}^{+}\right)-E_{\mathrm{p}}\left(\mathbf{4} / \mathbf{4}^{-}\right)-0.16
$$

From the CV data, we calculate the value of $\left|\Delta H_{\text {ann }}\right|$ to be $3.73 \mathrm{eV}$; this value is larger than the lowest excited singlet energy, $E_{\mathrm{s}}=3.46 \mathrm{eV}$, calculated from the fluorescence emission. This result suggests that it is highly probable for the ion annihilation process to occur via the S-route and that the ECL of $\mathbf{4}$ is an energy-sufficient system.

In conclusion, we have established an efficient synthesis of a novel carbazole-based molecule (4), in which electronegative pyrimidine rings have been introduced as electron-accepting moieties. The structural character of 4 is not only beneficial to the stability of its electrogenerated radical ions, but it also increases the possibility for generating the ECL. The high thermal and morpho- logical stability of $\mathbf{4}$, together with the high quantum efficiency of its photoluminescence in solid films, makes this new material suitable for further applications in OLEDs. Accordingly, we are currently preparing a deep-blue OLED device using $\mathbf{4}$ as an emission layer; the results will be reported in due course.

\section{Acknowledgements}

We thank the National Science Council and the Ministry of Education of Taiwan for financial support.

\section{Supplementary data}

Supplementary data associated with this article can be found, in the online version, at doi:10.1016/j.tetlet. 2004.11.166.

\section{References and notes}

1. (a) Richter, M. M. In Optical Biosensors: Present and Future; Ligler, F. S., Rowe Taitt, C. A., Eds.; Elsevier: Amsterdam, 2002; Chapter 6; (b) Lai, R. Y.; Chiba, M.; Kitamura, N.; Bard, A. J. Anal. Chem. 2002, 74, 551-553; (c) Bruce, D.; Ricther, M. M. Analyst 2002, 127, 14921495; (d) Dennany, L.; Forster, R. J.; Rusling, J. F. J. Am. Chem. Soc. 2003, 125, 5213-5218.

2. Lai, R. Y.; Fabrizio, E. F.; Lu, L.; Jenekhe, S. A.; Bard, A. J. J. Am. Chem. Soc. 2001, 123, 9112-9118.

3. Faulkner, L. R.; Bard, A. J. Electrogenerated chemiluminescence. In Electrochemical Methods; John Wiley \& Sons: New York, 1980; pp 621-627.

4. Faulkner, L. R.; Bard, A. J. In Electroanalytical Chemistry; Bard, A. J., Ed.; Marcel Dekker: New York, 1977; Vol. 10, pp 1-95.

5. (a) Noffsinger, J. B.; Danielson, N. D. Anal. Chem. 1987, 59, 865-868; (b) Miao, W.; Choi, J.-P.; Bard, A. J. J. Am. Chem. Soc. 2002, 124, 14478-14485.

6. (a) Abruna, H. D.; Bard, A. J. J. Am. Chem. Soc. 1982, 104, 2641-2642; (b) Elliott, C. M.; Pichot, F.; Bloom, C. J.; Rider, L. S. J. Am. Chem. Soc. 1998, 120, 6781-6784; (c) Anderson, A.-M.; Isovitsch, R.; Miranda, D.; Wadhwa, S.; Schmehl, R. H. Chem. Commun. 2000, 505-507.

7. (a) Kundu, P.; Justin Thomas, K. R.; Lin, J. T.; Tao, Y.-T.; Chuen, C.-H. Adv. Func. Mater. 2003, 13, 445-452; (b) Justin Thomas, K. R.; Lin, J. T.; Tao, Y.-T.; Ko, C.-W. J. Am. Chem. Soc. 2001, 123, 9404-9411.

8. (a) Wong, K.-T.; Hung, T. S.; Lin, Y.-T.; Wu, C.-C.; Lee, G.-H.; Peng, S.-M.; Chou, C. H.; Su, Y. O. Org. Lett. 2002, 4, 513-516; (b) Wu, C.-C.; Lin, Y.-T.; Chiang, H.-H.; Cho, T.-Y.; Chen, C.-W.; Wong, K.-T.; Liao, Y.-L.; Lee, G.-H.; Peng, S.-M. Appl. Phys. Lett. 2002, 81, 577-579.

9. To a solution of 2-(4-tert-butylphenyl)-5-bromopyrimidine $^{2} \quad(3 ; \quad 611 \mathrm{mg}, 2.1 \mathrm{mmol}), \quad \mathrm{Pd}\left(\mathrm{PPh}_{3}\right)_{4} \quad(231 \mathrm{mg}$, $0.2 \mathrm{mmol})$, and 5,8-bis(4,4,5,5-tetramethyl-[1,3,2]-dioxaborolan-2-yl)-1-phenylcarbazole $(2 ; 495 \mathrm{mg}, 1 \mathrm{mmol})$ in a mixture of toluene $(30 \mathrm{~mL})$ and $2 \mathrm{M} \mathrm{Na}_{2} \mathrm{CO}_{3(\mathrm{aq})}(3 \mathrm{~mL})$ was added $\mathrm{P}^{t} \mathrm{Bu}_{3}(0.05 \mathrm{M}$ in toluene, $2.0 \mathrm{~mL}, 0.10 \mathrm{mmol})$. The solution was refluxed with vigorous stirring for $72 \mathrm{~h}$ under a nitrogen atmosphere. The mixture was poured into water and extracted with chloroform. The organic extracts were washed with brine and dried over $\mathrm{MgSO}_{4}$. 
The solvent was removed by rotary evaporation, and the residue was purified by column chromatography (silica gel, ethyl acetate/hexane $=1 / 6)$ to provide $444 \mathrm{mg}(67 \%)$ of the product.
10. Chen, F.-C.; Ho, J.-H.; Chen, C.-Y.; Su, Y. O.; Ho, T.-I. J. Electroanal. Chem. 2001, 499, 17-23.

11. Faulkner, L. R.; Tachikawa, H.; Bard, A. J. J. Am. Chem. Soc. 1972, 94, 691-699. 